\title{
EDTA dependent pseudothrombocytopenia caused by antibodies against the cytoadhesive receptor of platelet gpIIB-IIIA
}

\author{
A Casonato, A Bertomoro, E Pontara, D Dannhauser, A R Lazzaro, A Girolami
}

\begin{abstract}
Aims-To clarify the mechanisms involved in the development of EDTA dependent pseudothrombocytopenia, particularly the platelet receptors.

Methods-Platelets were measured in 33 patients with pseudothrombocytopenia, using different anticoagulants to collect blood samples (direct test). The results were compared with the counts obtained by adding patients' serum or immunoglobulins to normal blood samples (indirect test). The role of platelet function was explored using ASA, PGE1, and apyrase as platelet inhibitors. The contribution of platelet receptor/s was investigated using antigens to gpIb-IX and gpIIb-IIIa monoclonal antibodies. Immunoglobulin class was estimated by the ability of IgG, IgA, and IgM antibodies to prevent platelet clumping.
\end{abstract}

Results-Agglutinating antibodies were IgA in $40 \%$, IgG in $30 \%$, and IgM in $10 \%$ of patients studied. Both patients' serum and immunoglobulins induced platelet clumping in normal samples anticoagulated with EDTA (indirect test). This was prevented by incubation of blood samples at $37^{\circ} \mathrm{C}$ and almost completely inhibited by the platelet inhibitors ASA, PGE1, and apyrase. Pseudothrombocytopenia was also entirely prevented by an antigen to gpIIb-IIIa monoclonal antibody that recognises fibrinogen and the von Willebrand factor binding site. Pseudothrombocytopenia was almost completely abolished after the addition of RGD peptide, the recognition sequence of cytoadhesive proteins.

Conclusions-These findings suggest that EDTA dependent pseudothrombocytopenia is caused by agglutinating antibodies that recognise cytoadhesive receptors on platelet gpIIb-IIIa and that an efficient platelet metabolism is required.

(F Clin Pathol 1994;47:625-630)

Pseudothrombocytopenia is the result of a spuriously low platelet count induced by agglutinating antibodies that cause in vitro platelet clumping. ${ }^{1-4}$ The condition is seen most often in blood samples anticoagulated with EDTA, although citrate, oxalate, or heparin have also been implicated. ${ }^{5-7}$ Most of the agglutinins react most strongly at room temperature or below, but some are temperature independent or react best at $37^{\circ} \mathrm{C} .^{8}$ Most are IgG, but IgM, IgA, and combinations of IgG and IgM or IgG and IgA also have been described. ${ }^{6-11}$

That platelet glycoprotein (gp) IIb-IIIa is involved in the EDTA induced antibody reaction was suggested by the observation that platelets from patients with Glanzmann's disease do not react with these antibodies. ${ }^{9}$ Identification of cold antibody (IgM) directed against platelet $\mathrm{gpIIb}^{6}$ that causes pseudothrombocytopenia is further support for this hypothesis. No abnormalities of platelet function have been described in association with EDTA dependent pseudothrombocytopenia.

\section{Methods}

Thirty three patients with EDTA dependent pseudothrombocytopenia were studied: eight men (mean (SEM) age 41.1 (16.2) years) and 25 women (mean (SEM) age $43.9(17 \cdot 4)$ years). Most (18 of 33) were healthy at the time of presentation. In the others, pseudothrombocytopenia was associated with various diseases (table).

The samples for platelet count were drawn from the antecubital vein, using $10 \mathrm{mM}$ EDTA, $0.38 \%$ sodium citrate, $10 \mathrm{IU}$ heparin or $1 \%$ ammonium oxalate using the Unopette system (Becton Dickinson, USA) as anticoagulants. ${ }^{12}$ Platelet counts were performed after two hours of incubation at $22^{\circ} \mathrm{C}$. Only individual platelets were counted. Platelet counts and the presence of platelet aggregates were determined by phase contrast microscopy. For each sample, counting was performed blind at least three times. Differences between the counts were always below $10 \%$. The size of platelet aggregates was expressed as the number of platelets involved.

In a direct test platelet counts were obtained for patients' blood samples. Indirect tests or mixing experiments were carried out by adding one part of the patient's serum or purified immunoglobulins to one part of normal blood. The platelet counts were performed after two hours of incubation at $22^{\circ} \mathrm{C}$.

Monoclonal antibodies and inhibitors of platelet function (ASA, PGE1, and apyrase) were included into the anticoagulants for blood collection in the direct tests. In the indirect experiments monoclonal antibodies and antiplatelet drugs were added to normal blood samples. After 30 minutes of incubation at 


\begin{tabular}{|c|c|c|c|c|c|}
\hline No & Sex & Age (years) & Associated diseases & $\begin{array}{l}\text { Citrate platelet } \\
\text { count } \times 10^{9} / l\end{array}$ & $\begin{array}{l}\text { EDTA platelet } \\
\text { count } \times 10^{9} / l\end{array}$ \\
\hline 1 & $\mathrm{~F}$ & 70 & Hypertension & 194 & 40 \\
\hline 2 & $\mathrm{~F}$ & 53 & Diabetes, hypertension & 264 & 180 \\
\hline 3 & $\mathrm{~F}$ & 55 & Gallstones, hypertension & 352 & 72 \\
\hline 4 & $\mathrm{~F}$ & 32 & Nephrolithiasis & 266 & 112 \\
\hline 5 & $\mathrm{M}$ & 65 & Recurrent cystourethritis & 196 & 104 \\
\hline 6 & $\mathrm{~F}$ & 34 & Hyperthyroidism & 273 & 127 \\
\hline 7 & $\mathrm{~F}$ & 38 & Hyperthyroidism & 238 & 76 \\
\hline 8 & $\mathrm{~F}$ & 60 & Ulcerative colitis & 140 & 44 \\
\hline 9 & $\mathrm{~F}$ & 56 & Gastroduodenal ulcer & 308 & 84 \\
\hline 10 & $\mathrm{~F}$ & 60 & Hemiplegia & 268 & 134 \\
\hline 11 & $\mathrm{~F}$ & 40 & Ovariectomy & 318 & 80 \\
\hline 12 & $\mathrm{~F}$ & 60 & Marfan's syndrome & 132 & 44 \\
\hline 13 & $M$ & 40 & Buerger's disease & 316 & 134 \\
\hline 14 & $M$ & 10 & Thrombocytopenia & 452 & 158 \\
\hline 15 & M & 55 & Pleuritis tuberculosis & 193 & 114 \\
\hline 16 & $\mathbf{M}$ & 27 & Asymptomatic & 270 & 32 \\
\hline 17 & $\mathrm{~F}$ & 46 & Asymptomatic & 188 & 64 \\
\hline 18 & $M$ & 65 & Asymptomatic & 220 & 32 \\
\hline 19 & $\mathrm{~F}$ & 20 & Asymptomatic & 256 & 80 \\
\hline 20 & $\mathrm{~F}$ & 27 & Asymptomatic & 213 & 53 \\
\hline 21 & $\mathrm{~F}$ & 44 & Asymptomatic & 216 & 132 \\
\hline 22 & $\mathrm{~F}$ & 75 & Asymptomatic & 158 & 32 \\
\hline 23 & M & 45 & Asymptomatic & 286 & 96 \\
\hline 24 & $\mathrm{~F}$ & 30 & Asymptomatic & 204 & 56 \\
\hline 25 & $\mathrm{~F}$ & 32 & Asymptomatic & 173 & 100 \\
\hline 26 & $\mathrm{~F}$ & 23 & Asymptomatic & 193 & 114 \\
\hline 27 & $\mathrm{~F}$ & 52 & Asymptomatic & 195 & 72 \\
\hline 28 & $\mathrm{~F}$ & 60 & Asymptomatic & 283 & 200 \\
\hline 29 & $\mathrm{~F}$ & 20 & Asymptomatic & 242 & 134 \\
\hline 30 & $\mathrm{~F}$ & 25 & Asymptomatic & 142 & 42 \\
\hline 31 & M & 22 & Asymptomatic & 200 & 48 \\
\hline 32 & $\mathrm{~F}$ & 20 & Asymptomatic & 246 & 46 \\
\hline 33 & $\mathrm{~F}$ & 45 & Asymptomatic & 284 & 114 \\
\hline
\end{tabular}

$22^{\circ} \mathrm{C}$ patients' sera or immunoglobulins were added and platelets were counted two hours later. In the indirect tests goat anti-human immunoglobulins were also used. Serum or ammonium precipitate $(100 \mu \mathrm{l})$ was incubated with $25 \mu \mathrm{l}$ of anti-human IgG $(2 \cdot 3$ $\mathrm{mg} / \mathrm{ml})$ or anti-human $\operatorname{IgM}(1.075 \mathrm{mg} / \mathrm{ml})$ or anti-IgA $(2.5 \mathrm{mg} / \mathrm{ml})$ (final concentration) for 10 minutes at $22^{\circ} \mathrm{C}$, without stirring. Then $100 \mu \mathrm{l}$ of EDTA blood sample was added and platelet number was measured two hours later. An anti HLA-DL monoclonal antibody (B 33.3) was used as the control in one experiment.

The bleeding time was measured using a Simplate II bleeding time device (General Diagnostic, Morris Plains, New Jersey, USA).

Immunoglobulins were purified by initial precipitation of patients' sera with $40 \%$ ammonium sulphate. The precipitate was then centrifuged at $10000 \times \mathrm{g}$ for 20 minutes dissolved in phosphate buffered saline (PBS) and dialysed against PBS overnight and applied to protein-G sepharose (Pharmacia, Sweden) to separate the IgG fraction. The concentration of IgG fraction, diluted in PBS buffer, ranged from $1246 \mathrm{mg} \%$ to $1800 \mathrm{mg} \%$.

Monoclonal antibodies against platelet gpIb-IX (LJIB1) and antigen to gpIIb-IIIa complex (LJCP8) were prepared and characterised, as described elsewhere. ${ }^{1314}$ LJIB1 recognises the von Willebrand factor binding site and completely inhibits ristocetin induced platelet aggregation. LJCP8 recognises fibrinogen, von Willebrand factor and the fibronectin binding site. In the experiments using blood from the patient with afibrinogenaemia, 1 volume of EDTA afibrinogenaemic blood was added to 1 volume of patient's serum. After two hours at $22^{\circ} \mathrm{C}$ platelets were counted. As a control normal and afibrinogenaemic blood samples were anticoagulated with citrate.

\section{Results}

Pseudothrombocytopenia was diagnosed from the following criteria: (1) reduction of the platelet count to less than $100 \times 10^{9} / 1$, depending on the anticoagulant used for blood collection; (2) presence of platelet aggregates in EDTA anticoagulated samples; (3) normal bleeding time associated with lack of history or physical findings indicative of a thrombocytopenic state.

Platelet counts were carried out using EDTA, sodium citrate, ammonium oxalate or

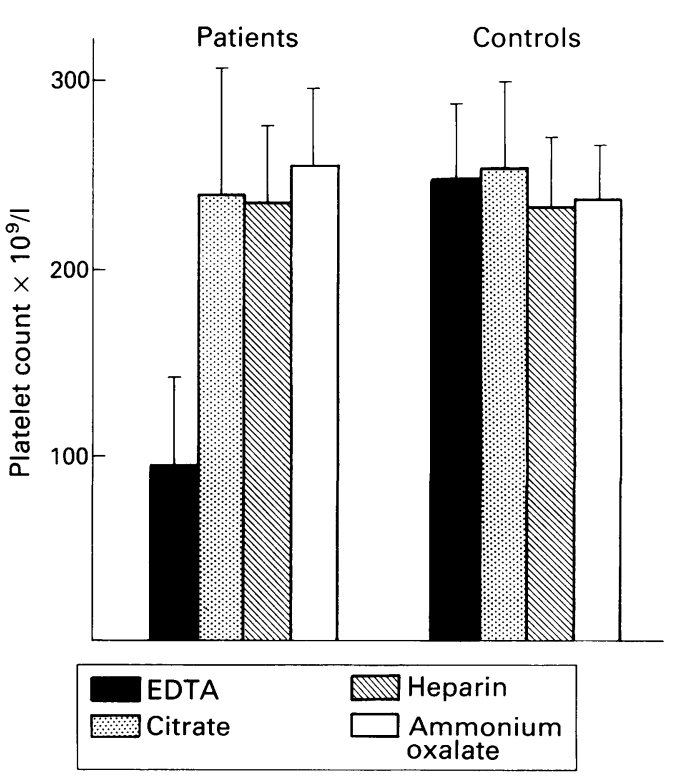

Figure 1 Mean platelet counts $\left(10^{9} / l\right)$ for patient and normal blood samples anticoagulated with $5 \mathrm{mM}$ EDTA, $0.38 \%$ sodium citrate, $1 \%$ ammonium oxalate (Unopette) or10 IU/ml heparin. After two hours of incubation at $22^{\circ} \mathrm{C}$, without stirring, platelets were counted. 
A

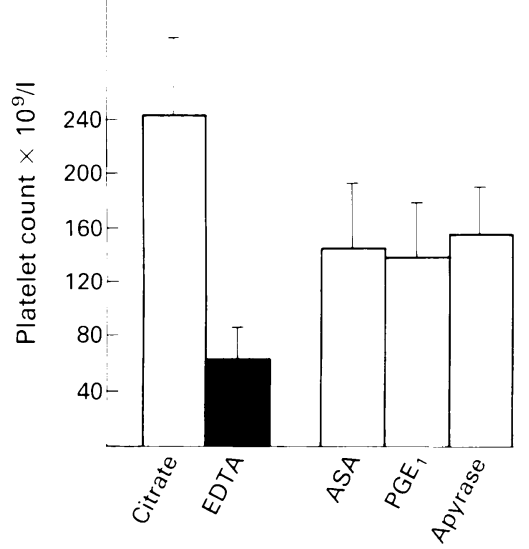

B

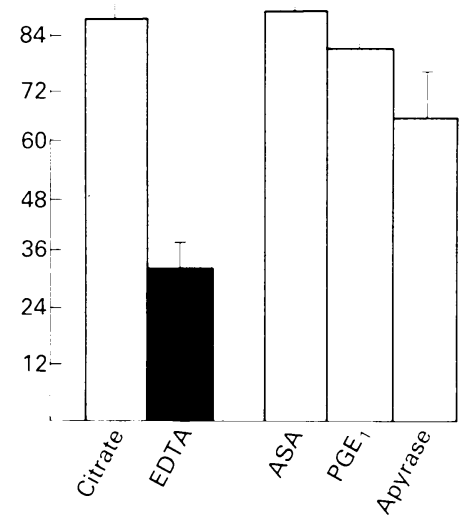

Figure 2 Effects of platelet inhibitors ( $A S A, P G E 1$, and apyrase) on the platelet clumping in direct $(A)$ and indirect $(B)$ tests. (A) The inhibitors were added to the anticoagulants used for blood collection. Platelet counts were performed after two hours of incubation at $22^{\circ} \mathrm{C}$. (B) The inhibitors were added to the normal blood. After 30 minutes of incubation at $22^{\circ} \mathrm{C}$, patient serum was added. Platelets were counted two hours later. ASA was $1 \mathrm{mg} / \mathrm{ml}$ in the direct and $2 \mathrm{mg} / \mathrm{ml}$ in the indirect test; PGE1 $42 \cdot 1 \mathrm{mM}$ in the direct and $21.2 \mathrm{mM}$ in the indirect experiments; apyrase was $10 \mathrm{IU} / \mathrm{ml}$ in both tests. The lower platelet count obtained in the indirect test depended on the diluting effect of patient serum. aggregates, constituted by three to five elements, were present. There was no evidence of platelet satellitism or of giant platelets in any of the samples..$^{1516}$

Serum or ammonium precipitate $(100 \mu \mathrm{l})$ or IgG fraction from all the patients, incubated with normal blood sample $(100 \mu \mathrm{l})$ (indirect experiments), induced platelet clumping when the blood was anticoagulated with EDTA, but not when anticoagulated with citrate or heparin. Platelet clumping was prevented by prior incubation of patient serum or ammonium precipitate with antigens to IgG, IgM, and IgA antibodies. The results were expressed in per cent, setting at $100 \%$ the platelet count obtained in samples anticoagulated with citrate. Platelet clumping was abolished when the values obtained ranged from $87 \%$ to $115 \%$. These findings, together with IgG purification, identified the immunological class of agglutinating antibodies. The antibodies were found to be IgA in $40 \%$ of the patients studied, IgG in $50 \%$, and $\operatorname{IgM}$ in $10 \%$. No combinations were found.

The effect of temperature on pseudothrombocytopenia was investigated by incubating blood samples from normal subjects at $37^{\circ} \mathrm{C}$ for 30 minutes before the addition of patient serum. Neither a decrease in platelet number or formation of platelet aggregates was observed. The mean (SEM) platelet count, obtained with 10 patient sera, was 134 $(49 \cdot 6) \times 10^{9} / 1$ at $37^{\circ} \mathrm{C}$, compared with 40 (18) $\times 10^{\%} / 1$ at $22^{\circ} \mathrm{C}$ or $140(52) \times 10^{9} / 1$ in the samples anticoagulated with citrate. An intermediate value $\left(80(36 \cdot 6) \times 10^{9} / 1\right)$ was found when normal blood and patient serum were incubated together at $37^{\circ} \mathrm{C}$.

Platelet metabolism was investigated using ASA, PGE1, and apyrase as platelet inhibi-

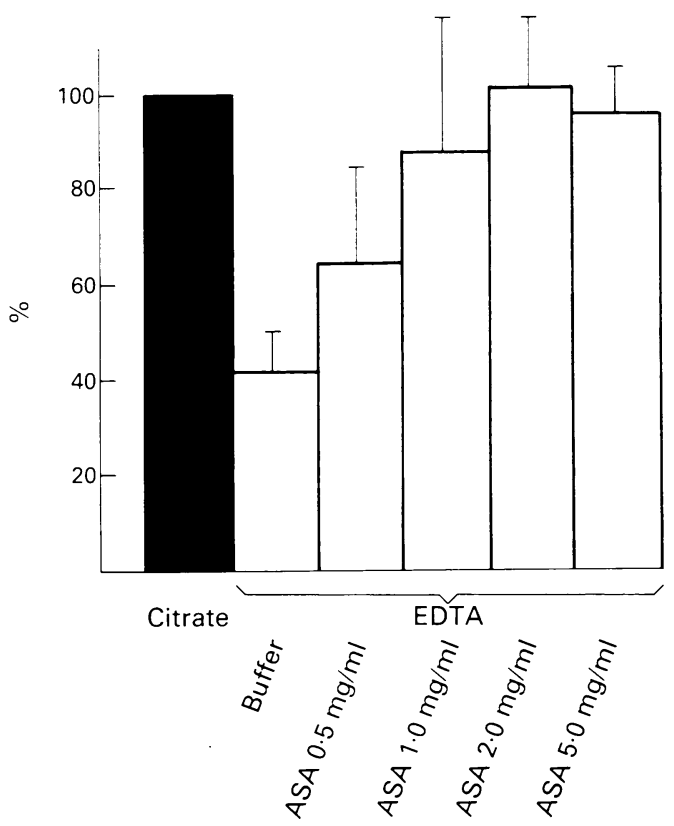

Figure 3 Dose response curves in the prevention of platelet clumping using different concentrations of $A S A$, in indirect experiments (see fig 2). The results are expressed in per cent, setting the count obtained when samples were anticoagulated with citrate at $100 \%$.
Figure 4 Mean platelet count $\left(10^{4} / \mathrm{l}\right)$ for patients' EDTA anticoagulated blood samples in the presence of anti-gpIb-IX (LFIB1 $100 \mu \mathrm{g} / \mathrm{ml})$ and antigen to gpIIbIIIa (LFCP8, $330 \mu \mathrm{g} / \mathrm{l})$ monoclonal antibodies compared with samples collected with sodium citrate. Monclonal antibodies were added to the anticoagulants and platelets were counted after two hours of incubation at $22^{\circ} \mathrm{C}$. Similar results were obtained in the indirect experiments. 
Figure 5 Prevention of platelet clumping by increasing concentrations of LFCP8 monoclonal antibody in indirect experiments. Normal EDTA anticoagulated blood was incubated with LFCP8 for 30 minutes at $22^{\circ} \mathrm{C}$. Then, an equal volume of patient serum was added. Platelets were counted 2 hours later. The results are expressed as the percentage of the maximal platelet count obtained with samples

anticoagulated with sodium citrate. different concentrations of

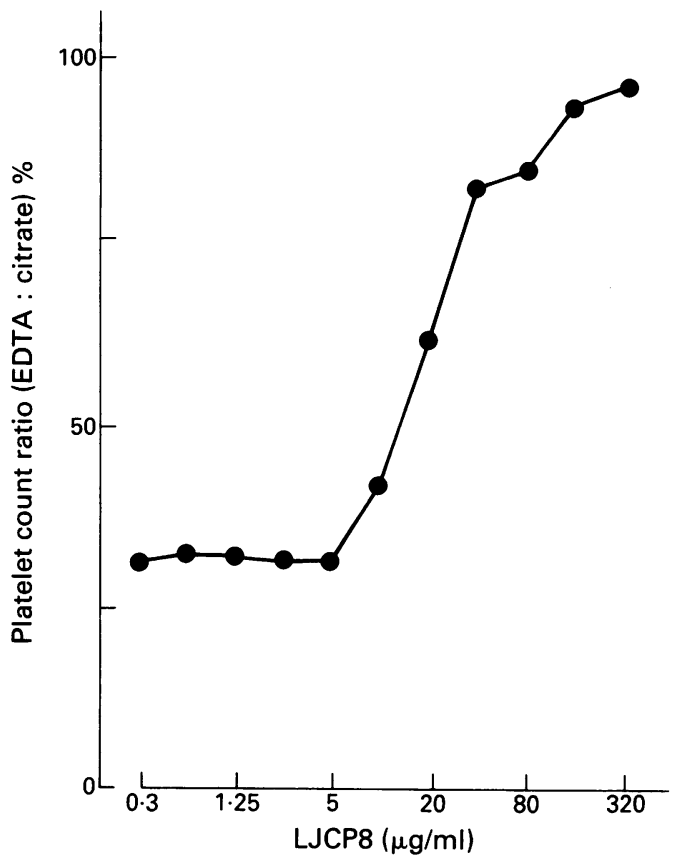

tors. In the direct tests platelet clumping was partially prevented by the addition of $\mathrm{mg} / \mathrm{mL}$ ASA, lower concentrations having no effect. The formation of platelet aggregates was also partially inhibited by $42.3 \mathrm{mM}$ PGE 1 and $10 \mathrm{IU} / \mathrm{ml}$ apyrase (fig $2 \mathrm{~A}$ ). In the indirect test, on the contrary, platelet clumping was completely inhibited by ASA $(2 \mathrm{mg} / \mathrm{ml})$, PGE1 $(21.2 \mathrm{mM})$, and apyrase $(10 \mathrm{IU} / \mathrm{ml})$ (fig 2B).

A dose response association was observed for ASA (fig 3): there was almost complete prevention of platelet clumping with 1,2 , and $5 \mathrm{mg} / \mathrm{ml} \mathrm{ASA}$, but lower concentrations had a lesser effect. It should be noted that when the concentration of ASA was reduced the stan-

Figure 6 Prevention of platelet clumping by increasing concentrations of $R G D$ peptide, in the indirect experiments (see fig 5). The results are expressed in per cent, with the counts for samples collected with sodium citrate set at $100 \%$. Similar results were observed in direct tests.

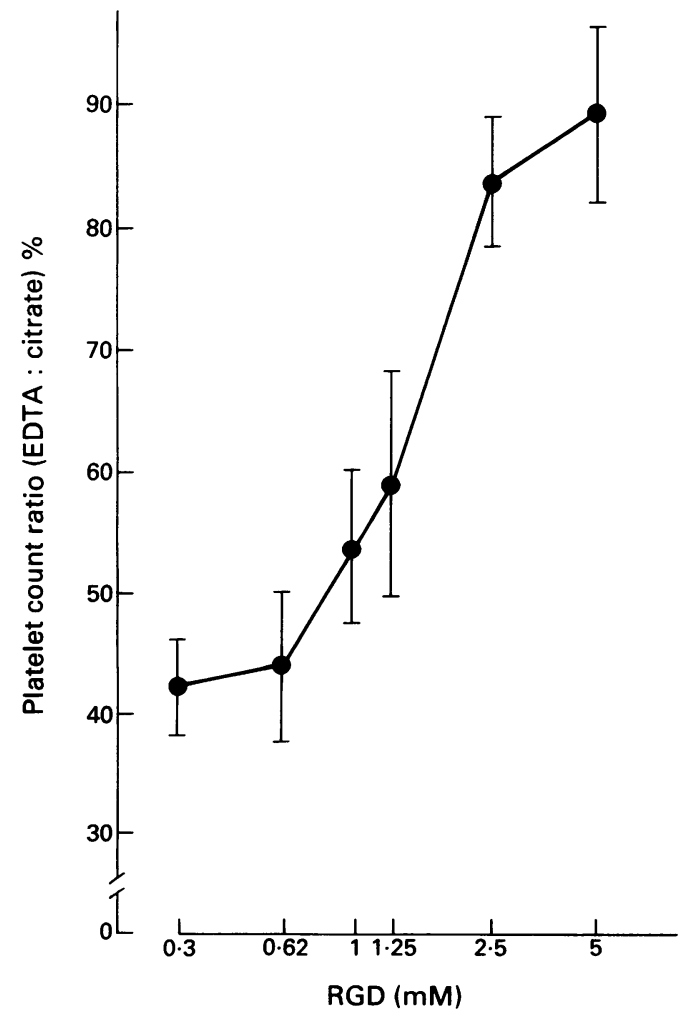

dard deviation increased, due to differences between the patients, in the minimal dose of ASA required to prevent the pseudothrombocytopenia phenomenon.

ASA was also administered in vivo $(600 \mathrm{mg}$ daily for a week) in four patients. In vivo the drug did not affect the development of pseudothrombocytopenia. Similarly, when ASA (600 mg daily) was administered in vivo to the donor for the indirect test, platelet clumping was not prevented in vitro.

To clarify the role of platelet receptor/s, antigens to platelet gpIb-IX (LJIB1, 100 $\mathrm{mg} / \mathrm{ml}$ ) and gpIIb-IIIa (LJCP8, $330 \mu \mathrm{g} / \mathrm{ml}$ ) monoclonal antibodies were used. LJIB1, which recognises the von Willebrand factor binding site on gpIb-IX, did not change either the platelet count or the presence of platelet aggregates (fig 4). In contrast, LJCP8, which recognises the von Willebrand factor and fibrinogen binding site on gpIIb-IIIa, completely inhibited pseudothrombocytopenia and the effect was dose-dependent (fig 5). A maximal effect was observed with monoclonal antibody concentrations between $330 \mu \mathrm{g} / \mathrm{ml}$ and $165 \mu \mathrm{g} / \mathrm{ml}$, with a rapid decrease between $80 \mu \mathrm{g} / \mathrm{ml}$ and $5 \mu \mathrm{g} / \mathrm{ml}$. Similar results were obtained in both the direct and indirect experiments. The specificity of LJCP8 in the prevention of platelet clumping was tested with Arg-Gly-Asp (RGD) peptide. As shown in fig 6 , when patients' blood samples were incubated with increasing concentrations of RGD peptide, there was the platelet count progressively increased. Platelet clumping was completely inhibited by $5 \mathrm{mM}$ RGD, while there was a rapid reduction in the effects at doses ranging between 2.5 and $1 \mathrm{mM}$. Lower concentrations had no effect. The dose-response relation of LJCP8 inhibition, resembling a sigmoid curve, was similar to that observed for RGD peptide.

The contribution of soluble fibrinogen was explored in the indirect test, with EDTA anticoagulated blood from a patient with afibrinogenaemia (fibrinogen below $20 \mathrm{mg} \%$ ). After the addition of the patient's serum the decrease in platelet count observed in the afibrinogenaemic blood sample was similar to those in normal blood $\left(58 \times 10^{9} / 1\right.$ v $46 \times 10^{9} / 1$ compared with $119 \times 10^{9} / 1$ and $132 \times 10^{9} / 1$, respectively, using citrated samples).

\section{Discussion}

EDTA dependent pseudothrombocytopenia consists of spuriously low platelet counts caused by the presence of platelet agglutinating antibodies that induce "in vitro" platelet clumping when the blood samples have been collected in EDTA.

We have shown, in this study, that the platelet site to which EDTA dependent agglutinins bind is the adhesive receptor on gpIIbIIIa, and that normal platelet function seems to be required for the occurrence of platelet clumping. Platelet gpIIb-IIIa, a member of the integrin family, ${ }^{17} 18$ has a crucial role in haemostasis by binding fibrinogen and von Willebrand factor during the formation of the 
platelet plug. ${ }^{19}$ gpIIb-IIIa is a $\mathrm{Ca}++$ dependent heterodimer. Removal of calcium by chelation causes loss of gpIIb-IIIa receptor function, and, at temperatures above $25^{\circ} \mathrm{C}$, dissolution of the gpIIb-IIIa complex into its individual subunits. ${ }^{20}$ The binding of $\mathrm{Ca}++$ by EDTA also affects the formation of the gpIIb-IIIa complex. ${ }^{7}$ We surmise that under our experimental conditions EDTA caused a change in the formation of the gpIIb-IIIa complex into some epitope/s available to platelet agglutinating antibodies.

The dissociation of the complex, after incubation of platelets with $5 \mathrm{mM}$ EDTA at $37^{\circ} \mathrm{C}$, strongly diminished the expression of this epitope and prevented the development of pseudothrombocytopenia.

The epitope to which agglutinins bind seems to be related to the LJCP8 monoclonal antibody, which is directed against the cytoadhesive receptor for gpIIb-IIIa of stimulated and unstimulated platelets. ${ }^{14}$ In all the patients studied LJCP8 prevented platelet clumping in a dose dependent and saturable manner. That this effect is specific seems to be confirmed by the finding that pseudothrombocytopenia was also prevented by the RGD peptide, which is the recognition sequence for adhesive proteins. ${ }^{21}$ The doseresponse association with the RGD peptide was similar to that seen with LJCP8. This seems to suggest that both events are the consequence of occupation of the same site. Furthermore, the sigmoid nature of the kinetics for both suggests cooperation of the mechanisms responsible for the inhibition of pseudothrombocytopenia.

Soluble fibrinogen does not seem to be necessary, because platelet clumping can be induced in blood from an afibrinogenaemic patient by the patient's agglutinins. ${ }^{22}$ On the other hand, platelet clumping seems to require normal platelet metabolism, as inhibitors of platelet activation, such as ASA, PGE1, and apyrase, prevent the phenomenon. This was incomplete in the direct experiment. In contrast, there was almost complete inhibition of pseudothrombocytopenia in the indirect test. These differences may be the result of the method of sample processing: in the indirect test platelets were incubated with the inhibitors prior to the addition of patients' agglutinins; in the direct test this was done afterwards. Furthermore, the inhibition of platelet clumping became evident only at doses significantly higher than those which normally inhibit platelet function. This could explain the failure of ASA administered in vivo to modify pseudothrombocytopenia. The requirement for normal platelet metabolism seems to suggest that the EDTA dependent clumping is an aggregation rather than an agglutination phenomenon. But in contrast to classic platelet aggregation, which requires binding of fibrinogen to the cytoadhesive receptor of gpIlb-IIIa, ${ }^{23}$ soluble fibrinogen does not seem to be required for the development of pseudothrombocytopenia.

The pathophysiology of antibody production is unknown and the various diseases found in some of the patients studied do not offer any clues. As in other reported studies, ${ }^{24}$ most of our patients were female, and most of them healthy at the time of presentation..$^{25} 26$ The diseases present were heterogeneous ${ }^{27-29}$ and not associated with autoimmune or clinically evident neoplastic pathology. ${ }^{30}$

In conclusion, our findings suggest that the cytoadhesive receptor on gpIIb-IIIa has a role in EDTA dependent pseudothrombocytopenia, which also seems to require normal platelet metabolism. An epitope which normally participates in platelet function becomes available after an EDTA dependent conformational change of gpIIb-IIIa and mediates an aggregation phenomenon that does not seem to require the fibrinogen molecule.

This work was supported by a Grant from MURST, Rome (06-1990) and by a grant from the Veneto Region.

The anti HLA-DL monoclonal antibody was kindly provided by Dr B Perussia, Winston Institute, Philadelphia. Dr Ruggier (San Diego, California) provided monoclonal antibodies to platelet gpIb-IX and gpIlb-IIa.

1 Gowland E, Kay HEM, Spillman JC, Williamson JR. Agglutination of platelets by a serum factor in the presAgglutination of platelets by a serum factor in
ence of EDTA. $\mathcal{F}$ Clin Pathol 1969;22:460-4.

2 Berning H, Stilbo I. Pseudothrombocytopenia and the hematology laboratory. Lancet 1982;ii:1469-70.

3 Rhee CY. Spurious thrombocytopenia. $\mathfrak{F A M A} 1974 ; 228$ : 3098 .

4 Kjeldsberg CR, Hershgold EJ. Spurious thrombocytopenia. $¥ A M A$ 1974;227:628-30

5 Onder O, Weinstein A, Hoyer L. Pseudothrombocytopenia caused by agglutinins that are reactive in blood anticoagulated with chelating agents. Blood 1980; 56:177-82.

6 Payne BA. EDTA-induced pseudothrombocytopenia: recognizing a laboratory artifact. Postgrad Med $\mathcal{F} 1985 ; 77$ ognizin.

7 Shreiner DR, Bell WR. Pseudothrombocytopenia: manifestation of a new type of platelet agglutinin. Blood 1973;42:541-9.

8 Pegels JG, Bruynes ECE, Engelfriet CP, Von dem Borne AEK. Pseudothrombocytopenia: an immunological study on platelet antibodies dependent on ethylen diamine tetraacetate. Blood 1982;59:157-61.

9 Veenhoven WA, Van Der Schans GS, Huiges W, et al. Pseudothrombocytopenia due to agglutinins. Am $\mathcal{f}$ Clin Pathol 1979;72:1005-8.

10 Van Vliet HHD, Kappers-Klunne MC, Abels J. Pseudothrombocytopenia: a cold antibody agains platelet glycoprotein gpIIb. Br $\mathcal{f}$ Haematol 1986;62: p01-11.

11 Himai H, Nakamoto Y, Miki K, et al. Pseudothrombocytopenia and IgA-related platelet agglutinin in a patien with IgA nephritis. Nephron 1983;34:154-8.

12 Casonato A, Sartori MT, De Marco L, Girolami A. 1desamino-8-d-arginine vasopressin (DDAVP) infusion in type IIB von Willebrand's disease: shortening of bleeding time and induction of variable pseudothrombocytopenia. Thromb Haemostas 1990;64:117-9.

13 Handa $M$, Titani $K$, Holland LL, et al. The von Willebrand factor binding domain of platelet membrane glycoprotein $\mathrm{Ib}$. Characterization by monoclonal antiglycoprotein $\mathrm{Ib}$. Characterization by monoclonal antibodies and partial aminoacid sequence analysis of

14 Niiya $K$, Hodson E, Bader $R$, et al. Increased surface expression of the platelet membrane glycoprotein IIbIIIa complex induced by platelet activation. Relationship to the binding of fibrinogen and platelet aggregation. Blood 1987;70:475-83.

15 Kjelsberg CR, Swanson JL. Platelet satellitism. Blood 1974;43:831-7.

16 Griepp PR, Gralnick HR. Platelet to leukocyte adherence phenomenon associated with thrombocytopenia. Blood 1976;47:513-21.

17 Hynes RO. Integrins: a family of cell surface receptors. Cell 1987;48:549-54.

18 Ruoslahti E. Platelet membrane gpIIb-IIIa member of a family of Arg-Gly-Asp-specific adhesion receptors. Science of Arg-Gly-Asp-sp

19 Bennet JS, Vilaire G. Exposure of platelet fibrinogen receptor by ADP and epinephrine. $\boldsymbol{f}$ Clin Invest receptor by $\mathrm{AD}$

20 Phillips DR, Charo IF, Scarborough RM. gpIIb-IIIa: the responsive integrin. Cell 1991;65:359-62.

21 Pierschbacher MD, Ruoslahti E. Variants of the cell recognition site of fibrinonectin that retain attachment pro- 
moting activity. Proc Nat Acad Sci USA 1984;81:5985-8.

22 De Marco L, Girolami A, Zimmerman TS, Ruggeri ZM.

von Willebrand factor interaction with the glycoprotein IIb-IIIa complex: its role in platelet function as demonstrated in patients with congenital afibrinogenemia. $\mathcal{F}$ Clin Invest 1986;77:1272-7.

23 Plow EF, D'Souza ST, Ginsberg MH. Consequences of the interaction of platelet membrane glycoprotein GPIIb-IIIa (IIb-3) and its ligands. $\mathcal{F}$ Lab Clin Med 1992; 120:198-204.

24 Berkman N, Michaeli Y, Reuven O, Eldor A. EDTAdependent pseudothrombocytopenia: a clinical study of 18 patients and a review of the literature. Am $\mathcal{F}$ Hematol 1991;36:195-201.

25 Castaman G, Ruggeri M, Rodeghiero M. EDTA-dependent pseudothrombocytopenia. Am $\mathcal{f}$ Hematol 1992;41: 226.
26 Garcia Suarez J, Calero MA, Ricard MP, et al. EDTAdependent pseudothrombocytopenia in ambulatory patients: clinical characteristics and role of new automated cell-counting in its detection. Am $\mathcal{f}$ Hematol 1992;39:146-7.

27 Boehme WM, Mahmood T, Phanuphak P. Pseudothrombocytopenia associated with vasculitis. $A m \mathcal{F}$ Med thrombocytopenia associated with vasculitis. Am 9 Med
Sci $1980 ; 279: 125-8$.

28 Imai H, Nakamoto Y, Miki K, et al. Pseudothrombocytopenia and IgA-related platelet agglutinin in patients with IgA nephritis. Nephron 1983;34:154-8.

29 Solanki DL, Blackburn BC. Spurious thrombocytopenia during pregnancy. Obstet Gynecol 1985;65:14S-17S

30 Veenhoven WA, Van der Schans GS, Nieweg HO. Monoclonal immunoglobulins with affinity for platelets and their relationship to malignant lymphoma. Cancer 1982;49:40-2. 